\title{
Multiple matings affect the reproductive performance of the aphidophagous ladybird beetle, Coelophora saucia (Coleoptera: Coccinellidae)
}

\author{
OMKAR, SATYENDRA K. SINGH and GeETANJALi MISHRA
}

Ladybird Research Laboratory, Department of Zoology, University of Lucknow, Lucknow-226007, India; e-mail: omkaar55@hotmail.com

Key words. Coccinellidae, Coelophora saucia, ladybird, fecundity, multiple mating, egg viability, longevity

\begin{abstract}
The effect of multiple matings on the readiness with which mating occurred, fecundity, egg viability and adult longevity in the aphidophagous ladybird beetle, Coelophora saucia (Mulsant) (Coleoptera: Coccinellidae), was investigated under laboratory conditions. The time to onset of mating after previous pairing was found to decrease with increase in the number of matings. Multiply mated females had a higher fecundity and egg viability than single mated females. The trends in the results were analyzed using both binomial regression and the Gompertz equation. The best fitting curve was that based on the binomial equation, which indicates that $95 \%$ of the maximum theoretical fecundity was attained after mating 11 times and $95 \%$ of the maximum theoretical egg viability after mating 3 times. Unlike previous studies on ladybirds, a slight but statistically significant increase in female longevity was observed with increase in number of matings indicating that the male ejaculate might provide a supply of nutrients.
\end{abstract}

\section{INTRODUCTION}

In most organisms mating is either monogamous or promiscuous. Multiple mating with more than one male within a single breeding season is reported for a number of insects (Olsson et al., 1994; Eberhard, 1996; Zeh, 1997). This may act as an insurance against male infertility (Sheldon, 1994), reduce the risk of sperm depletion (Bourne, 1993), eliminate problems of sperm incompatibility (Zeh, 1997), allow females to select the highest quality sperm (Olsson et al., 1996) or increase genetic variation amongst offspring (Majerus 1994; Ward \& Landolt 1995; Yasui, 1998). Multiple matings also help females to accrue direct material benefits such as an adequate supply of sperm (Drnevich et al., 2001), defensive chemicals (González et al., 1999), nutrients and/or oviposition stimulants (Wagner et al., 2001). In addition, it is also associated with a number of costs, such as, loss of time and energy, risk of predation and infection by sexually transmitted diseases (Daly, 1978; Martens \& Rehfeldt, 1989; Hurst et al., 1995; Blanckenhorn et al., 2002).

Most of these benefits, however, do not accrue when the multiple matings are with the same male. Yet multiple matings with the same male is recorded in insects (see Arnqvist \& Nilsson, 2000). The possible benefits of multiply mating with the same male are increase in life-time reproductive success (Alcock et al., 1978; Majerus, 1994; Ward \& Landolt, 1995) and nutritional gifts (Arnqvist \& Nilsson, 2000). Multiply mated females usually lay more eggs than single mated females (Ridley, 1988; Arnqvist \& Nilsson, 2000; Drnevich et al., 2001; Vahed, 2003). Multiple mating has a more pronounced affect on egg production in species with nuptial feeding (Arnqvist \& Nilsson, 2000). Despite the poor benefits for the female, multiple matings with a single male is reported in number of insects. Usually one or few matings are supposed to suffice for females but not males (Bateman, 1948). The question therefore arises as to what are the advantages of multiple mating? Based on fitness benefits, multiple mating by males is easier to explain than that by females. However, the two events are interrelated.

The apparent absence of fitness benefits in females provokes the question: why do they indulge in multiple matings? Up to what number of matings, do the benefits outweigh the costs? What is the optimal number of matings required for maximizing fitness of both males and females? Also, is the optimal number of matings the same or different in the two sexes? These and many other questions have been actively debated by evolutionary biologists in recent years using insect models (Arnold \& Duvall, 1994; Tregenza \& Wedell, 1998; Arnqvist \& Nilsson, 2000; Wedell et al., 2002; Nilsson, 2004). The emphasis in most studies has been on determining the optimal number of matings and its divergence or compliance with that recorded in nature.

There are, however, few studies on multiple mating in ladybirds, though its occurrence in the wild and laboratory is reported (Brakefield, 1984; Majerus, 1994; Osawa, 1994; Ransford, 1997; Haddrill, 2001; Webberly et al., 2006) The ladybirds, Anatis ocellata Linnaeus (Kesten, 1969), Adalia bipunctata (Semyanov, 1970), Coccinella septempunctata Linnaeus (Omkar \& Srivastava, 2002), Cheilomenes sexmaculata (Fabricius), Coccinella transversalis Fabricius (Omkar, 2004; Omkar \& James, 2005), and pale morph of Propylea dissecta (Mulsant) (Omkar \& Pervez, 2005) lay greater numbers of eggs of higher viability when mated frequently as opposed to once. However, this is not the case in Adalia bipunctata, where egg production and hatching are not influenced by either the number of matings (Hadrill et al., 2007; Perry \& 
Rowe, 2008) or mates (Hadrill et al., 2007). In many ladybirds multiple matings and increased fecundity are associated with a short adult life (Rawat \& Modi, 1969; Babu \& Ananthakrishnan, 1993; Agarwala \& Choudhuri, 1995), which indicates a possible reproduction-longevity trade-off (Mishra \& Omkar, 2006). This is evident even when the spermatophores are consumed by the females, as reported in A. bipunctata (Perry \& Rowe, 2008). Optimal mating rates have been determined for the ladybirds, C. sexmaculata and P. dissecta (Omkar et al., 2006).

Despite a few seminal works on optimal number of matings in ladybirds more studies are needed. The present study aims to determine the number of matings for optimal reproductive performance in both sexes of the aphidophagous ladybird, Coelophora saucia, which is an important natural enemy of aphids and mealybugs infesting various economically important agricultural, horticultural and ornamental crops (Dai, 1990; Pathak, 2008). The identification of the optimal number of matings may also help enhance the mass multiplication of this potential biocontrol agent.

\section{MATERIAL AND METHODS}

\section{Stock maintenance}

Adults of C. saucia were collected from local agricultural crops of Dolichos lablab Linnaeus infested with the aphid, Aphis craccivora Koch. They were paired in Petri dishes $(9.0 \times$ $2.0 \mathrm{~cm}$ ) and reared in the laboratory on the same prey-host-plant complex at $25 \pm 2{ }^{\circ} \mathrm{C}, 60 \pm 5 \% \mathrm{RH}$ and a photoperiod of $14 \mathrm{~L}$ : 10D. Larvae that hatched from eggs laid by these beetles were reared to the pupal stage on a daily replenished supply of prey in glass beakers $(11.0 \times 9.0 \mathrm{~cm})$. The adults that emerged from the pupae were sexed, separated and kept under the same conditions as the larvae.

\section{Experimental design}

Ten-day-old virgin adults (male and female) were paired in Petri dishes with an ad libitum supply of prey at $1000 \mathrm{~h}$ and kept under observation until $1800 \mathrm{~h}$. If the adults did not mate they were rejected. Those that mated were separated and mated again the next day. In this way, adults were subjected to the requisite number of matings $(1,3,5,7,10$, or 20 matings) with a single mating per day. Previous observations on the stock culture indicated that one mating per day is realistic. There were 10 replicates per mating treatment. Time to commencement of each mating, oviposition period, fecundity and viability of the eggs (number of eggs that hatched of the total number laid per repli- cate per treatment) laid after the requisite number of matings was achieved. Eggs laid before the ladybird had been mated for to the requisite number of times were not included. Male and female longevities were also recorded.

\section{Statistical analysis}

Bartlett's test indicated that the results were normally distributed. To determine the effect of multiple matings, the data (time to commencement of last mating, oviposition period, fecundity, egg viability, male and female longevity) were subjected to a one-way ANOVA followed by post hoc Tukey's test of significance using statistical software Minitab (Minitab, 2003). Time to commencement of $1^{\text {st }}, 3^{\text {rd }}, 5^{\text {th }}, 7^{\text {th }} 10^{\text {th }}$ and $20^{\text {th }}$ matings in the different treatments was also compared using one-way ANOVA.

The trends in the relationships between fecundity and egg viability, and the number of matings were analyzed using polynomial regression and the Gompertz equation. This method of analysis was previously used to describe similar trends in two other ladybirds (Omkar et al., 2006).

The Gompertz equation is as follows:

$$
\mathrm{Yt}=\mathrm{Ae}^{-\mathrm{Be}(-\mathrm{kt})}
$$

where $\mathrm{Yt}$ is predicted fecundity or egg viability at $\mathrm{t}$ matings; A is the asymptote (maximum fecundity or egg viability); e the logarithm; $\mathrm{k}$ the rate of growth (slope); B the constant of integration and $t$ the number of matings.

The regression coefficients of the different equations were compared using $\chi^{2}$ test for determining best fit. The best fitting equations were used to determine the relationships between fecundity and egg viability, and the number of matings. The resultant curves were used to determine the number of matings that resulted in $95 \%$ and $50 \%$ of maximum theoretical fecundity and egg viability. The optimal number of matings for females is that which resulted in $95 \%$ of the theoretical fecundity and for males $95 \%$ of the theoretical egg viability.

\section{RESULTS}

The time to the commencement of last mating was found to decrease significantly with an increase in the number of matings $(\mathrm{F}=22.17$; d.f. $=5,54$; $\mathrm{P}<0.001)$. Pairs took the least amount of time to start copulating at the $20^{\text {th }}$ mating and the most at the first mating. The average time to commencement of mating did not differ significantly between the 1 and 3, 3, 5, 7 and 10, and 7, 10 and 20 matings. There was no difference in the time to commencement of $1^{\text {st }}(\mathrm{F}=2.30$; d.f. $=5,54 ; \mathrm{P}>0.05), 3^{\text {rd }}$ $(\mathrm{F}=1.36 ;$ d.f. $=4,45 ; \mathrm{P}>0.05), 5^{\text {th }}(\mathrm{F}=2.99 ;$ d.f. $=3$, $36 ; \mathrm{P}>0.05), 7^{\text {th }}(\mathrm{F}=1.05 ;$ d.f. $=2,27 ; \mathrm{P}>0.05)$ and $10^{\text {th }}$

TABLE 1. Effect of multiple matings on the reproductive attributes of Coelophora saucia.

\begin{tabular}{ccccccc}
\hline $\begin{array}{c}\text { No. of } \\
\text { matings }\end{array}$ & $\begin{array}{c}\text { Time to start of last } \\
\text { mating (in s) }\end{array}$ & Fecundity & $\begin{array}{c}\text { Percentage } \\
\text { egg viability }\end{array}$ & $\begin{array}{c}\text { Oviposition } \\
\text { period }\end{array}$ & $\begin{array}{c}\text { Female } \\
\text { longevity }\end{array}$ & $\begin{array}{c}\text { Male } \\
\text { longevity }\end{array}$ \\
\hline 1 & $8.45 \pm 0.75^{\mathrm{c}}$ & $1506.40 \pm 98.51^{\mathrm{a}}$ & $89.32 \pm 0.88^{\mathrm{a}}$ & $53.70 \pm 0.93^{\mathrm{a}}$ & $56.20 \pm 1.58^{\mathrm{a}}$ & $63.20 \pm 9.50^{\mathrm{cd}}$ \\
3 & $7.63 \pm 0.75^{\mathrm{bc}}$ & $1692.20 \pm 85.37^{\mathrm{a}}$ & $93.03 \pm 1.09^{\mathrm{b}}$ & $57.60 \pm 1.64^{\mathrm{b}}$ & $62.60 \pm 1.81^{\mathrm{b}}$ & $60.50 \pm 2.17^{\mathrm{d}}$ \\
5 & $7.06 \pm 0.62^{\mathrm{b}}$ & $1882.80 \pm 54.95^{\mathrm{b}}$ & $94.84 \pm 1.19^{\mathrm{b}}$ & $62.50 \pm 1.66^{\mathrm{c}}$ & $64.30 \pm 2.08^{\mathrm{bc}}$ & $55.70 \pm 1.70^{\mathrm{c}}$ \\
7 & $4.75 \pm 0.35^{\mathrm{ab}}$ & $1944.90 \pm 56.78^{\mathrm{b}}$ & $94.90 \pm 0.62^{\mathrm{bc}}$ & $63.20 \pm 1.30^{\mathrm{c}}$ & $65.60 \pm 1.75^{\mathrm{c}}$ & $50.10 \pm 0.88^{\mathrm{b}}$ \\
10 & $3.69 \pm 1.27^{\mathrm{ab}}$ & $2163.40 \pm 82.80^{\mathrm{c}}$ & $95.80 \pm 0.72^{\mathrm{c}}$ & $65.50 \pm 1.06^{\mathrm{cd}}$ & $68.20 \pm 1.60^{\mathrm{d}}$ & $48.90 \pm 1.48^{\mathrm{ab}}$ \\
20 & $2.44 \pm 0.15^{\mathrm{a}}$ & $2192.20 \pm 99.93^{\mathrm{c}}$ & $96.34 \pm 0.72^{\mathrm{c}}$ & $66.10 \pm 1.75^{\mathrm{d}}$ & $69.40 \pm 2.10^{\mathrm{d}}$ & $47.80 \pm 1.44^{\mathrm{a}}$ \\
\hline F-value & 22.17 & 10.54 & 7.80 & 11.54 & 6.52 & 9.99 \\
\hline
\end{tabular}

Values are Means \pm S.E. F-values are significant at $\mathrm{P}<0.001$. Same letter in each column denotes that the means are not significantly different. 


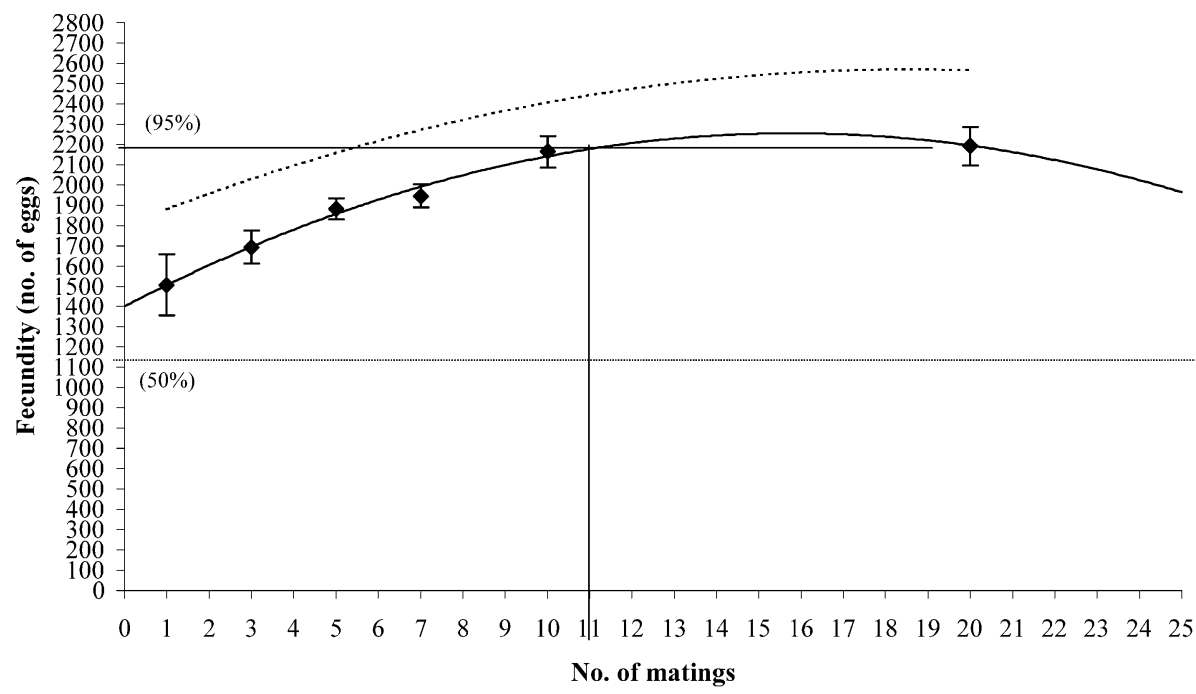

Fig. 1. The relationship between average fecundity $( \pm \mathrm{SE})$ and number of times a female of $C$. saucia was mated. The complete curved line is that derived using a Binomial regression analysis of the results and the dashed line using the Gompertz equation. The former gave the best fit and was used to determine the minimum number of times a female needs to be mated to achieve the maximum fecundity. Data in parentheses indicate $\%$ of maximum fecundity.

$(\mathrm{F}=122 ;$ d.f. $=1,18 ; \mathrm{P}>0.05)$ matings in the different treatments.

The oviposition period increased significantly with increase in number of matings and was highest for 20 matings $(\mathrm{F}=11.54 ; \mathrm{df}=5,54 ; \mathrm{P}<0.001)$. However, there were no significant differences between individual means after five matings. Fecundity also increased with increase in number of matings and was maximum for females that were mated 20 times $(\mathrm{F}=10.54 ; \mathrm{df}=5,54 ; \mathrm{P}<0.001$; Table 1). There were no significant differences between the fecundity of females mated 1 and 3, 5 and 7, and 10 and 20 times.

Maximum egg viability was recorded for eggs laid by females after 20 matings, and the minimum after a single mating $(\mathrm{F}=7.80 ; \mathrm{df}=5,54 ; \mathrm{P}<0.001$; Table 1$)$. However, egg viability of females mated 3,5 and 7 times, and 7, 10 and 20 times did not differ significantly.

Female longevity increased slightly with increase in number of matings $(\mathrm{F}=6.52$; d.f. $=5,54 ; \mathrm{P}<0.001)$. It was shortest for females mated once and longest for those mated 20 times. The longevites of females that were mated 3 and 5, 5 and 7, and 10 and 20 times did not differ. Male longevity, on the other hand, decreased with increase in number of matings $(\mathrm{F}=9.99$; d.f. $=5,54 ; \mathrm{P}<$ 0.001 ) and was shortest for those that mated 20 times. The longevities of the males that were mated 1 and 3,1 and 5, 7 and 10, and 10 and 20 times did not differ significantly.

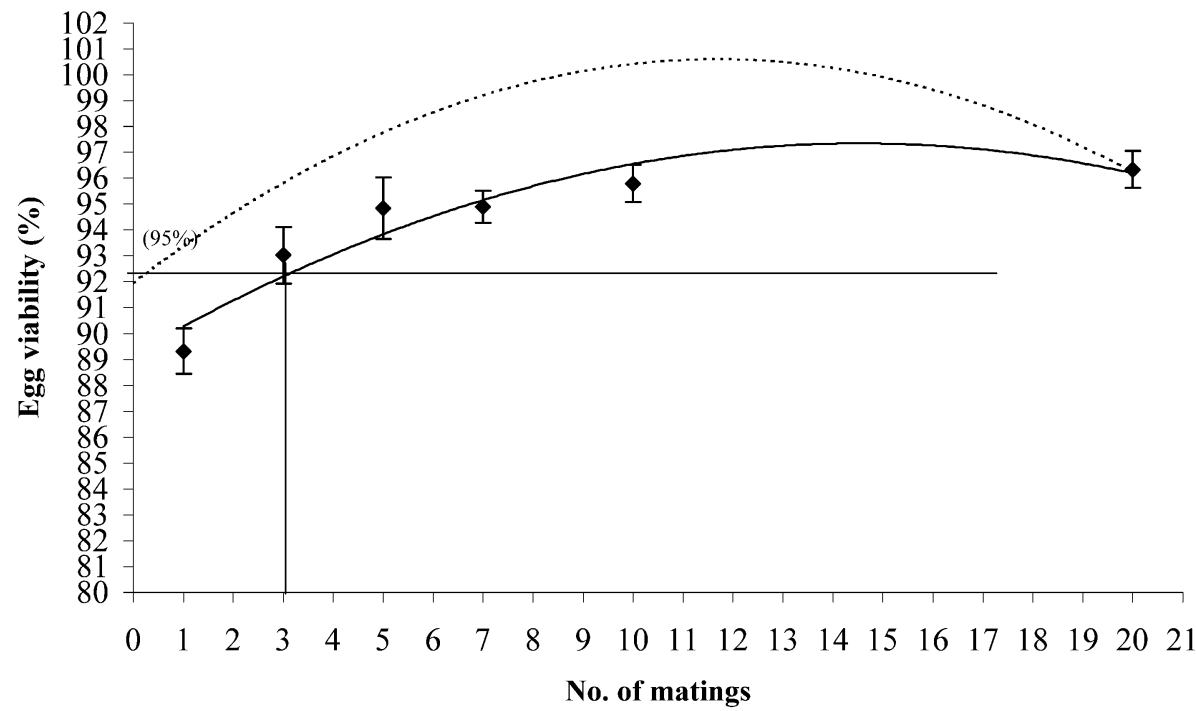

Fig. 2. The relationship between average egg viability $( \pm \mathrm{SE})$ and number of times a female of $C$. saucia was mated. The complete curved line is that derived using a Binomial regression analysis of the results and the dashed line using the Gompertz equation. The former gave the best fit and was used to determine the minimum number of times a female needs to be mated to achieve maximum egg viability during its lifetime. Data in parentheses indicate the $\%$ of maximum viability. 
Comparison of the regression coefficients of the curves fitted to the relationship between fecundity and the number of times the females were mated using a binomial regression equation $\left(\mathrm{y}=-3.4298 \mathrm{x}^{2}+108.25 \mathrm{x}+1400.9\right.$; $\left.\mathrm{R}^{2}=0.99 ; \mathrm{P}<0.001\right)$ and Gompertz equation ( $\mathrm{y}=$ $\left.-2.2437 \mathrm{x}^{2}+83.21 \mathrm{x}+1799.9 ; \mathrm{R}^{2}=0.90 ; \mathrm{P}<0.001\right)$ indicated that the former resulted in a better fit $\left(\chi^{2}=4.61 ; \mathrm{P}<\right.$ $0.05)$ than the latter. A similar comparison of the binomial regression $\left(\mathrm{y}=-0.0386 \mathrm{x}^{2}+1.1231 \mathrm{x}+89.188 ; \mathrm{R}^{2}=\right.$ $0.90 ; \mathrm{P}<0.001)$ and Gompertz $\left(\mathrm{y}=-0.0632 \mathrm{x}^{2}+1.4788 \mathrm{x}\right.$ $\left.+91.965 ; \mathrm{R}^{2}=0.51 ; \mathrm{P}<0.01\right)$ curves for the relationship between egg viability and the number of times the females were mated also revealed that the former resulted in a better fit $\left(\chi^{2}=20.02 ; \mathrm{P}<0.001\right)$.

Thus, the binomial regression equation was used to determine the number of matings required to achieve $95 \%$ of the theoretical fecundity, which was 11 matings, which is thus the optimal number of matings for females. As the females always laid more eggs than $50 \%$ of the theoretical fecundity it was not possible to determine this parameter. A forward extrapolation of the best fitting binomial regression indicated a decline in fecundity after 17 matings. Thus females needed to be mated 3 times to achieve $95 \%$ maximum of the theoretical egg viability (Figs 1 and 2), and this is the optimal number of matings for males. Forward extrapolation of the egg viability curve revealed the presence of an asymptote. As the percentage of eggs that hatched was always above this limit it was not possible to determine the $50 \%$ theoretical egg viability for C. saucia.

\section{DISCUSSION}

The results reveal that multiple matings decrease the time to the start of mating, and increase fecundity and egg viability in C. saucia. The decrease in time to start of mating probably indicates familiarity with (a) the mate, and/ or (b) the process of mating. Which of these two factors is the most important in reducing the time to mating can be analyzed by subjecting males to multiple matings with different mates. The mating histories of the mates might also play a role in determining the nature of mating (Jones \& Elgar, 2004; Harris \& Moore, 2005; Marcotte et al., 2006; Wilder \& Rypstra, 2008). The time to commencement of mating is not affected by mating history in the oblique banded leafroller, Choristoneura rosaceana, and spruce budworm, Choristoneura fumiferana (Marcotte et al., 2005). In the ladybird, Coleomegilla maculata, isolation increases both the mating frequency and the time to commencement of mating (Harmon et al., 2008). Also, isolation affected males more than females indicating that both the initiation of mating and copulation are male dependent.

Fecundity was found to increase with the number of matings in C. saucia. There are a number of explanations for this phenomenon. Firstly, a single mating might not provide sufficient stimulants / hormones / nutrients to facilitate maturation and oviposition of all the eggs in the ovarioles (Tseng et al., 2007). Thus, one explanation for the increased fecundity of multiply mated females is the receipt of greater quantities of fecundity stimulants in the ejaculate (Arnqvist \& Nilsson, 2000). Increased fecundity with increase in number of matings is recorded for a few other ladybirds (Semyanov, 1970; Omkar \& Srivastava, 2002; Omkar, 2004; Omkar \& James, 2005; Omkar \& Pervez, 2005; Omkar et al., 2006), but not for A. bipunctata (Hadrill et al., 2007; Perry \& Rowe, 2008).

What is interesting is that the increase in fecundity with increase in number of matings in C. saucia is not linear. Fecundity in C. saucia first increased and then decreased with increase in the number of matings rather than increasing to a plateau, as in C. sexmaculata and $P$. dissecta (Omkar et al., 2006). An intermediate optimal number of matings is reported by Arnqvist \& Nilsson (2000), who established the existence of the optimal number of matings for a number of insect orders using meta-analysis. The optima may be determined by the maximum number of ovarioles present in the ovaries in each species (Stewart et al., 1991; Dixon \& Guo, 1993). The optimal number of matings is determined by this limitation on female fecundity (Bateman, 1948). This limitation on fitness associated with an upper limit on fecundity is not significantly affected by insect order or food availability. It is suggested that females that mate only a few times may minimize the cost of mating, while those that mate many times maximize the benefits of mating (LaMunyon \& Eisner, 1994; Wedell et al., 2002). In contrast Callosobruchus maculatus (Fabricius) (Nilsson, 2004) has a higher reproductive performance when mated either once or more than three times, than when mated twice.

The likely costs associated with mating are an: (1) increase in the likelihood of predation, (2) decrease in food consumption, (3) decrease in energy levels due to expenditure during mating. As the matings reported here were monogamous it is unlikely there was a destructive cocktail of chemicals in the ejaculate of the males (Duvoisin et al., 1999; Baer et al., 2000), which could have caused a reduction in the viability of the eggs.

Unlike in other ladybirds (Rawat \& Modi, 1969; Kariluoto, 1980; Agarwala \& Choudhuri, 1995; Mishra \& Omkar, 2006) there is an increase in female longevity with increase in the number of matings in $C$. saucia. Perry \& Rowe (2008) report that longevity in ladybirds is not decreased by multiple mating and the longevity of twice mated females of Callosobruchus maculatus is longer than that of single mated females (Tseng et al., 2007). The increase in longevity recorded for C. saucia females may be due to the presence of certain nutrients in the sperm ejaculate / spermatophore.

The increase in egg viability with increase in number of matings recorded in this study on C. saucia is also reported for a number of ladybirds (Kesten, 1969; Omkar \& Srivastava, 2002; Omkar, 2004; Omkar \& Pervez, 2005; Omkar et al., 2006). Given rapid sperm degeneration, multiple mating may serve to provide a female with an adequate supply of fresh sperm for fertilizing all her eggs. A deleterious effect of multiple matings is that male longevity decreased with increase in number of matings. 
This can be attributed to the increased utilization of energy resources in mating.

A finding of this study that differs from previous studies on ladybirds (Omkar et al., 2006) is that the optimal number of matings for females is higher than for males. The reasons for this are unknown and need further study.

Thus, this study reveals that multiple matings (a) reduce the time to the commencement of mating, (b) increase fecundity and egg viability, and (c) increase female longevity, which is contrary to previous findings. The results also reveal that there exists an optimal number of matings for both sexes and that for females it is higher than for males.

ACKNOWLEDGEMENTS. The first two authors thank the Council of Science and Industrial Research, New Delhi for financial assistance in the form of a research grant. Authors also express their thanks to anonymous reviewers and English editor for invaluable queries, suggestions and improvements in original draft.

\section{REFERENCES}

Agarwala B.K. \& Choudhuri M.S. 1995: Use of alternative food in rearing of aphidophagous ladybeetle, Menochilus sexmaculata. Entomon 20(2): 19-23.

Alcock J., Barrows E.M.G., Gordh L.J., Hubbard L., Kirkendale D., Pyle T., Ponder L. \& Zalom F.G. 1978: The ecology and evolution of male reproductive behaviour in the bees and wasps. Zool. J. Linn. Soc. 64: 293-326.

Arnold S.J. \& Duvall D. 1994: Animal mating systems: a synthesis based on selection theory. Am. Nat. 143: 317-348.

ARNQVist G. \& Nilsson T. 2000: The evolution of polyandry: multiple mating and female fitness in insects. Anim. Behav. 60: $145-164$.

Babu A. \& Ananthakrishnan T.N. 1993: Predatory efficiency, reproductive potential and bioenergetics of Coccinella transversalis F. and Menochilus sexmaculata F. (Coleoptera: Coccinellidae) in relation to (Homoptera: Aphididae) prey quality. Phytophaga 5: 121-133.

Baer B., Maile R., Schmid-Hempel P., Morgan E.D. \& Jones G.R. 2000: Chemistry of a mating plug in bumblebees. $J$. Chem. Ecol. 26: 1869-1875.

Bateman A.J. 1948: Intra-sexual selection in Drosophila. Heredity 2: 349-368.

Blanckenhorn W.U., Hosken D.J., Martin O.Y., Reim C., TeUSChL Y. \& WARD P.I. 2002: The cost of copulation in the dung fly Sepsis cynipsea. Behav. Ecol. 13: 353-358.

BouRNE G.R. 1993: Proximate costs and benefits of mate acquisition at leks of the frog Ololygon rubra. Anim. Behav. 45: 1051-1059.

BRAKEFIELD P.M. 1984: Ecological studies on the polymorphic ladybird Adalia bipunctata in the Netherlands. I. Population biology and geographical variation of melanism. J. Anim. Ecol. 53: 761-774.

DAI Z.Y. 1990: Seasonal occurrence of Coelophora saucia (Col.: Coccinellidae) and its predation rate on aphids. Chin. J. Biol. Cont. 6(3): 113-115.

Daly M. 1978: The cost of mating. Am. Nat. 112: 771-774.

Dixon A.F.G. \& Guo Y. 1993: Egg and cluster size in ladybird beetles (Coleoptera: Coccinellidae): the direct and indirect effects of aphid abundance. Eur. J. Entomol. 90: 457-463.

Drnevich J.M., Papke R.S., Rauser C.L. \& Rutowski R.L. 2001: Material benefits from multiple mating in female meal- worm beetles (Tenebrio molitor L.). J. Insect Behav. 14: 215-230.

Duvoisin N., Baer B. \& Schmid-Hempel P. 1999: Sperm transfer and male competition in the bumblebee, Bombus terrestris. Anim. Behav. 58: 743-749.

Eberhard W.G. 1996: Female Control: Sexual Selection by Cryptic Female Choice. Princeton University Press, Princeton, NJ.

GonzÁlez A., Rossini C., Eisner M. \& Eisner T. 1999: Sexually transmitted chemical defense in a moth (Utetheisa ornatrix). Proc. Natl. Acad. Sci. USA 96: 5570-5574.

HadDriLl P.R. 2001: The Development and Use of Molecular Genetic Markers to Study Sexual Selection and Population Genetics in the two-spot ladybird, Adalia bipunctata (L.). Ph.D. thesis, University of Cambridge.

Haddrill P.R., Shuker D.M., Mayes S. \& Majerus M.E.N. 2007: Temporal effects of multiple mating on components of fitness in the two-spot ladybird, Adalia bipunctata (Coleoptera: Coccinellidae). Eur. J. Entomol. 104: 393-398.

Harmon J.P., Hayden A. \& Andow W. 2008: Absence makes the heart grow fonder: Isolation enhances the frequency of mating in Coleomegilla maculata (Coleoptera: Coccinellidae). J. Insect Behav. 21: 495-504.

Harris W.E. \& Moore P.J. 2005: Female mate preference and sexual conflict: females prefer males that have had fewer consorts. Am. Nat. 165(5): S64-S71.

Hurst G.D.D., Sharpe R.G., Broomfield A.H., Walker L.E., Majerus T.M.O. \& ZaKharov I.A 1995: Sexually transmitted disease in a promiscuous insect, Adalia bipunctata. Ecol. Entomol. 20: 230-236.

Jones T.M. \& Elgar M.A. 2004: The role of male age, sperm age and mating history on fecundity and fertilization success in the hide beetle. Proc. R. Soc. Lond. (B) 271: 1311-1318.

Kariluoto K.T. 1980: Survival and fecundity of Adalia bipunctata (Coleoptera: Coccinellidae) and some predatory insect species on an artificial diet and a natural prey. Ann. Entomol. Fenn. 46: 101-106.

Kesten U. 1969: Zur morphologie und biologie von Anatis ocellata (L.) (Coeloptera, Coccinellidae). Z. Ang. Entomol. 63: 412-455.

LAMunYon C.W. \& EISNER T. 1994: Spermatophore size as determinant of paternity in an arctiid moth (Utetheisa ornatrix). Proc. Natl. Acad. Sci. USA 91: 7081-7084.

MaJerus M.E.N. 1994: Female promiscuity maintains high fertility in ladybirds (Coleoptera; Chrysomelidae). Entomol. Monthly Mag. 130: 205-209.

Marcotte M., Delisle J. \& McNeil J.N. 2005: Impact of male mating history on the temporal sperm dynamics of Choristoneura rosaceana and C. fumiferana females. J. Insect Physiol. 51: 537-544.

Marcotte M., Delisle J. \& Mcneil J.N. 2006: Impact of male mating history on the postmating resumption of sexual receptivity and lifetime reproductive success in Choristoneura rosaceana females. Physiol. Entomol. 31: 227-233.

Martens A. \& Rehreldt 1989: Female aggregation in Platycypha caligata (Odonata: Chlorocyphidae): a tactic to evade to male interference during oviposition. Anim. Behav. 37: 369-374.

MinitaB 2003: Minitab Statistical Software, Minitab Release 13. 2, Minitab Inc.

Mishra G. \& OMKar 2006: Ageing trajectory and longevity trade-off in a generalist aphidophagous ladybird, Propylea dissecta (Coleoptera: Coccinellidae). Eur. J. Entomol. 103: 33-40.

NiLsson T. 2004: Polyandry and the evolution of reproductive divergence in insects. $\mathrm{PhD}$ thesis, Umea University, Sweden. 
Olsson M., Madsen T., Shine R., Gullberg A. \& Tegelström H. 1994: Can female adders multiply? Reply. Nature 369: 528.

Olsson M., Shine R., Madsen T., Gullberg A. \& Tegelstrom H. 1996: Sperm selection by females. Nature 383: 585 .

OMKAR 2004: Reproductive behaviour of two aphidophagous ladybird beetles, Cheilomenes sexmaculata and Coccinella transversalis. Entomol. Sin. 11: 47-60.

OMKAR \& JAMES B.E. 2005: Reproductive behaviour of an aphidophagous ladybeetle, Coccinella transversalis Fabricius. Int. J. Trop. Insect Sci. 25: 96-102.

OMKAR \& Pervez A. 2005: Mating behaviour of an aphidophagous ladybird beetle, Propylea dissecta (Mulsant). Insect Sci. 12: 37-44.

OMKAR \& SRIVASTAVA S. 2002: The reproductive behaviour of an aphidophagous ladybeetle, Coccinella septempunctata Linnaeus. Eur. J. Entomol. 99: 465-470.

OMKaR, Mishra G. \& SingH S.K. 2006: Optimal number of matings of two aphidophagous ladybird beetle. Ecol. Entomol. 31: $1-4$.

Osawa N. 1994: The occurrence of multiple mating in a wild population of the ladybird beetle Harmonia axyridis Pallas (Coleoptera: Coccinellidae). J. Ethol. 12: 63-66.

Pатнак S. 2008: Life Attributes of an Aphidophagous Ladybird, Coelophora saucia (Mulsant). PhD. thesis, University of Lucknow, $223 \mathrm{pp}$.

PERRY J.C. \& ROWE L. 2008: Neither mating rate nor spermatophore feeding influences longevity in a ladybird beetle. Ethology 114: 504-511.

RANSFORD M.O. 1997: Sperm Competition in the 2-spot Ladybird, Adalia bipunctata. Ph.D. thesis, University of Cambridge.

Rawat R.R. \& Modi B.N. 1969: Studies on Nephus regularis (Coleoptera: Coccinellidae) as a predator of striped mealybug in Madhya Pradesh. Ann. Entomol. Soc. Am. 62: 953-956.

RiDLEY M. 1988: Mating frequency and fecundity in insects. Biol. Rev. 63: 509-549.

Semyanov V.P. 1970: Biological properties of Adalia bipunctata L. (Coleoptera: Coccinellidae) in conditions of Leningrad region. Zashch. Rast. Vredit. Bolez. 127: 105-112.
Sheldon B.C. 1994: Male phenotype, fertility, and the pursuit of extra-pair copulations by female birds. Proc. R. Soc. Lond. (B) 257: 25-30.

Stewart L.A., Hemptinne J.L. \& Dixon A.F.G. 1991: Reproductive tactics of ladybird beetles: relationship between egg size, ovariole number and development time. Func. Ecol. 5: $380-385$.

Tregenza T. \& Wedell N. 1998: Benefits of multiple mates in the cricket, Gryllus bimaculatus. Evolution 52: 1726-1730.

Tseng H.F., Yang R.L., Lin C. \& Horng S.B. 2007: The function of multiple mating in oviposition and egg maturation in the seed beetle Callosobruchus maculatus. Physiol. Entomol. 32: $150-156$.

VAHED K. 2003: Increases in egg production in multiply mated female bushcrickets Leptophyes punctatissima are not due to substances in the nuptial gift. Ecol. Entomol. 28: 124-128.

Wagner W.E., Kelley R.J., Tucker K.R. \& Harper C.J. 2001: Females receive a life-span benefit from male ejaculates in a field cricket. Evolution 55: 994-1001.

WARD K.E. \& LANDOLT P. J. 1995: Influence of multiple matings on fecundity and longevity of female cabbage looper moths (Lepidoptera: Noctuidae). Ann. Entomol. Soc. Am. 88: 768-772.

Webberly K.M., Buszko J., Isham V. \& Hurst G.D.D. 2006: Sexually transmitted disease epidemics in a natural population. J. Anim. Ecol. 75: 33-43.

Wedell N., Gage M.J.G. \& Parker G.A. 2002: Sperm competition, male prudence and sperm limited females. Trends Ecol. Evol. 17: 313-320.

Wilder S.M. \& Rypstra A.L. 2008: Prior encounters with the opposite sex affect male and female mating behavior in a wolf spider (Araneae, Lycosidae). Behav. Ecol. Soc. 62: 1813-1820.

Yasui Y. 1998: The 'genetic benefits' of female multiple mating reconsidered. Trends Ecol. Evol. 13: 246-250.

ZEH J.A. 1997: Polyandry and enhanced reproductive success in the harlequin-beetle-riding pseudoscorpion. Behav. Ecol. Sociobiol. 40: 119-126.

Received July 13, 2009; revised and accepted December 3, 2009 